\title{
Formulation and In vitro/In vivo Evaluation of Sustained Release Diltiazem Matrix Tablets
}

\author{
Dheeraj Baviskar ${ }^{1 \star}$, Rajesh Sharma ${ }^{2}$ and Dinesh Jain ${ }^{3}$ \\ ${ }^{1}$ Institute of Pharmaceutical Education, Boradi, Tal-Shirpur, Dist-Dhule, ${ }^{2}$ School of Pharmacy, D.A.V.V., Phashila Campus, \\ Khandwa Road, ${ }^{3}$ College of Pharmacy, I.P.S. Academy, Rajendra Nagar, Indore, India
}

*For correspondence: Email: baviskar@sancharnet.in; Tel: +91- 9850001942

\begin{abstract}
Purpose: To develop and optimise sustained release (SR) matrix tablets of diltiazem hydrochloride (DHL).

Methods: DHL tablets were prepared by direct compression and consisted of hydroxypropylmethylcellulose (HPMC), Kollidon SR and Eudragit RSPO. A $3^{2}$ full factorial design was applied to study the effect of polymers used on drug release from the DHL. The tablets were also evaluated for physicochemical characteristics and release kinetics. In vivo (human) studies were carried out on the optimised formulation using a commercial sustained release product as a reference.

Results: The physicochemical characteristics of all prepared tablets were satisfactory. The developed drug delivery system provided prolonged drug release rates over a period of $24 \mathrm{~h}$. The release profile of the developed formulation was described by the Higuchi model. Mean time to attain peak drug concentration $\left(T_{\max }\right)$ was $2.05 \pm 0.52$ and $2.30 \pm 0.57 \mathrm{~h}$ for the optimized and commercial formulations, respectively, while mean maximum drug concentration $\left(C_{\max }\right)$ was $501.74 \pm 0.05 \mathrm{ng} / \mathrm{ml}$ and $509.65 \pm 0.06, \mathrm{ng} / \mathrm{ml}$, respectively. A fair correlation between the dissolution profile and bioavailability for the optimized formulation was observed based on linear regression analysis.

Conclusion: A fair correlation between in vitro dissolution and in vivo data was found for the optimized formulation of diltiazem. The results also indicate that the approach used could lead to a successful development of a sustained release formulation of the drug.
\end{abstract}

Keywords: Diltiazem, Matrix tablet, Hydroxypropyl methylcellulose, Eudragit, Optimization

Tropical Journal of Pharmaceutical Research is indexed by Science Citation Index (SciSearch), Scopus, International Pharmaceutical Abstract, Chemical Abstracts, Embase, Index Copernicus, EBSCO, African Index Medicus, JournalSeek, Journal Citation Reports/Science Edition, Directory of Open Access Journals (DOAJ), African Journal Online, Bioline International, Open-J-Gate and Pharmacy Abstracts

\section{INTRODUCTION}

Compressed hydrophilic matrices have become popular as modified release dosage forms for oral administration in terms of clinical efficacy and patient compliance [1]. Matrix system is often used for manufacturing sustained-release dosage forms easy of production [2].

Diltiazem $\mathrm{HCl}$ is a water soluble calcium-channel blocker belonging to the benzothiazepine family. Calcium channel blockers affect the movement of calcium into the cells of the heart and blood vessels, relaxing the blood vessels and increasing blood supply and oxygen to the heart. They are generally used to treat high blood pressure, arrhythmia and angina pectoris [3].

There are several studies where the polymer type, composition, and tablet characteristics have been studied in order to achieve desired DHL release profile [4-6]. Carbopols, polyvinyl alcohol, sodium carboxymethylcellulose, carrageenan and xanthan gums are among the most widely in this regard [7-9]. Matrix tablets can be prepared 
by wet granulation or by direct compression [10]. These tablets, when prepared using HPMC $\mathrm{K} 15 \mathrm{M}$ CR, on contact with dissolution media or gastric fluids become hydrated to form a viscous gel layer through which drug will be released by diffusion and/or by erosion of the matrix [11]. However, the use of only hydrophilic polymers for extending drug release for highly water-soluble drugs is limited due to rapid diffusion of dissolved drug through hydrophilic gel networks. For such highly water soluble drugs, it becomes necessary to incorporate another type of polymer in the matrix system.

Among such polymers, Eudragit RLPO or RSPO have been used successfully to formulate appropriate sustained release matrix formulations [12-14]. The aim of the present study, therefore, was to design a sustained release matrix tablet capable of producing 20 $24 \mathrm{~h}$ sustained release of diltiazem $\mathrm{HCl}$ using a combination of hydrophobic and gelling hydrophilic polymer. A secondary objective was to evaluate the influence of polymer content and type as well as polymer combination on drug release profile.

\section{EXPERIMENTAL}

\section{Materials}

Diltiazem hydrochloride and magnesium stearate were received as gifts from Golden Cross Pharma (India). Hydroxypropyl methylcellulose (HPMC) K15M CR Premium and starch (Sta-RX 1500) were obtained from Colorcon Asia Private Ltd. (India) while polyvinyl acetate/polyvinylpyrrolidone (Kollidon SR) was supplied by BASF (India). Eudragit RSPO and the microcrystalline cellulose (MCC) were purchased from Evonik GmbH (Germany) and Ozone ${ }^{\circledR}$ International (India), respectively.

\section{Preparation of diltiazem tablets}

All the powder materials (drug and Excipients) were passed through a sieve of aperture size of $250 \mu \mathrm{m}$ and then blended in a polythene bag manually. The blends were directly compressed (with compressing weight of $502 \mathrm{mg}$ for tablets containing a single polymer and $452 \mathrm{mg}$ for combination of polymers) on a Cadmach single punch tablet machine (Ahmadabad, India) using $8 \mathrm{~mm}$ concave punches.

\section{Factorial design}

A $3^{2}$ factorial design was used in this study and two factors evaluated, each at three levels; experimental trials were performed at all nine combinations. Combinations of polymer HPMC K15 CR $\left(\mathrm{X}_{1}\right)$ and Eudragit RSPO $\left(\mathrm{X}_{2}\right)$ were selected as independent variables (Table 1 ). Drug release at 18 and $20 \mathrm{~h}$ was selected as dependent variables. The data were also subjected to $3 \mathrm{D}$ response surface methodology to determine the influence of polymer and binder on dependent variables.

All the batches each contained $100 \mathrm{mg}$ diltiazem hydrochloride, $11.95 \%$ Starch 1500, $2 \%$ talc, $0.39 \%$ magnesium stearate and MCC q.s. to produce tablets of $452 \mathrm{mg}$ weight.

Table 1: Formulation variables in a $3^{2}$ factorial design

\begin{tabular}{lccc}
\hline Factor & \multicolumn{3}{c}{ Level } \\
\hline & -1 & 0 & 1 \\
$\mathrm{X}_{1}:$ amount of HPMC & 150 & 170 & 190 \\
K15M CR $(\mathrm{mg})$ & & & \\
$\begin{array}{l}\mathrm{X}_{2}: \text { amount of } \\
\text { Eudragit RSPO }(\mathrm{mg})\end{array}$ & 60 & 80 & 100 \\
\hline
\end{tabular}

\section{Physicochemical characterization of powder blend}

Micromeritic properties of prepared powder blend were evaluated for powder flow, angle of repose, bulk density, \% compressibility (Carr's index) and Hausner's ratio, as per United States Pharmacopoeia (USP) 30-NF25 [15].

\section{Physical evaluation of diltiazem hydrochloride tablets}

Tablet hardness was determined with a Monsanto tablet hardness tester (Campbell Electronics, Mumbai, India). The individual hardness of 10 tablets randomly selected from each batch was measured and then mean and standard deviation taken. while friability was obtained with a friabilator (Hoffmann-La Roche Ltd., Basel, Switzerland). The weight of ten tablets before and after the test, and the percent loss in weight recorded as friability. The drug content of the tablets was evaluated spectrophotometrically (Shimadzu, model 1700) at $235 \mathrm{~nm}$.

\section{In vitro drug release studies}

In vitro drug release studies were carried out in $900 \mathrm{ml}$ of $0.1 \mathrm{M} \mathrm{HCl}$ for the first $2 \mathrm{~h}$ using a USP XXII type 1 dissolution apparatus (Electrolab TDT-08L) at $50 \mathrm{rpm}$ and $37 \pm 0.5{ }^{\circ} \mathrm{C}$. Immediately after, the dissolution medium replaced with $900 \mathrm{ml}$ of phosphate buffer $(\mathrm{pH}$ 6.8) that has been pre-equilibrated to $37^{\circ} \mathrm{C}$. At predetermined time intervals during the 
dissolution test, samples $(5 \mathrm{ml})$ were withdrawn for assay and replaced with equivalent volume of fresh medium to maintain conditions. All dissolution studies were performed in triplicate. The samples were filtered, diluted appropriately was and then analyzed for diltiazem spectrophotometrically (Shimadzu, Japan) at 235 $\mathrm{nm}$. The test was performed in triplicate.

\section{Kinetic analysis of dissolution data}

The release data were fitted to five kinetic models, viz, zero-order, first-order, Higuchi, Korsmeyer-Peppas and Hixson-Crowell to determine drug release mechanism with the aid of Expert 7.0.3 trial software, GraphPad Instat ${ }^{\circledR}$ (GraphPad Software Inc., San Diego, CA).

\section{In-vivo evaluation studies}

Bioavailability studies were carried out on the experimental formulation and commercial formulation, Diltime SR tablets (Zydus Medica, India) which served as the reference. The human study was approved and carried out in compliance with the protocol of institutional ethical committee (approval reference no. CPBEMV-112009 under CPU, India) based on the guidelines for bioavailability and bioequivalence studies (CDSCO, DGHS, India) [16]. The subjects enrolled in the study were presented with full details of the investigation, both verbally and in written form, prior to providing written informed consent.

\section{Study design}

Six healthy non-smoking adult male subjects between 20 and 29 years old $(24.7 \pm 3.4$ years) and weighing from 55 to $65 \mathrm{~kg}(61 \pm 5.1 \mathrm{~kg})$ were admitted to the intra-individual randomized threeperiod crossover single-dose study. The subjects received diltiazem $\mathrm{HCl}$ in each trial period, i.e., the test formulation $\left(\mathrm{DHE}_{9}\right)$ or Diltime SR (reference). Dosage form administration strictly adhered to the study protocol.

\section{Sample collection and analysis}

Blood samples $(5 \mathrm{ml})$ were collected from 0 to 48 $\mathrm{h}$ after administration of $\mathrm{DHE}_{9}$ and Diltime SR. Plasma was harvested by taking $0.5 \mathrm{~mL}$ of plasma in a vial, $100 \mu \mathrm{l}$ of $0.1 \mathrm{~N} \mathrm{HCL}$, was added and vortexed; $3 \mathrm{~mL}$ of ethyl acetate was added and again vortexed for $5 \mathrm{~min}$; the vials were centrifuged for $10 \mathrm{~min}$ at $4500 \mathrm{rpm}$ and $4{ }^{\circ} \mathrm{C}$; 2 $\mathrm{mL}$ of the organic upper layer was evaporated to dryness at $50 \stackrel{\circ}{\circ}$ under a steady stream of nitrogen and kept at $-20{ }^{0} \mathrm{C}$ pending analysis by high pressure liquid chromatography (HPLC).
Plasma diltiazem $\mathrm{HCl}$ concentration was determined by a HPLC method. Sample preparation was performed by liquid-liquid extraction in tert-butyl methyl ether. The organic solvent was evaporated and the residue dissolved in a mobile phase. Aliquots of $20 \mu \mathrm{L}$ were injected automatically into the chromatograph. Separation of diltiazem was achieved on reversed phase (C18) column with a mobile phase consisting of $10 \mathrm{mM}$ ammonium acetate: acetonitrile (55:45 v/v). Quantitation of diltiazem was performed by UV detector at 235 $\mathrm{nm}$.

Each sample was analysed in triplicate and the mean computed. Pharmacokinetics parameters, i.e., $\mathrm{C}_{\max }$ and $\mathrm{T}_{\max }$, were determined from plasa concentration versus time data, while $\mathrm{AUC}_{0-\mathrm{t}}$ was calculated from the mean plasma diltiazem $\mathrm{HCl}$ concentration-time data.

\section{Stability of test formulation}

The optimized batch $\mathrm{DHE}_{9}$ was kept for accelerated stability study at $40^{\circ} \mathrm{C} / 75 \% \mathrm{RH}$, as per $\mathrm{ICH}$ guidelines, for 6 months. The samples were analyzed for physical appearance, drug content and dissolution profiles.

\section{Statistical analysis}

For optimization of tablet formulations and data analysis, software, Opti-Stat (self developed version 1.0.0), was used. To compare the mean of all release data and to assess statistical differences between them, either single-factor analysis of variance (ANOVA) or unpaired twotailed t-test was carried out at $95 \%$ confidence level while multiple regression analysis was carried out using Design Expert 7.0.3 (StatEase).

\section{RESULTS}

\section{Physical characteristics of tablets}

The physical appearance, hardness, friability and drug content were well within the prescribed limits (Table 2). All the physical parameters of compressed tablets complied with the official requirements [15].

\section{Drug release from DHL matrix tablets}

The presence of polyvinyl acetate/polyvinylpyrrolidone (Kollidon SR) produced burst release profiles. Table 3 shows release profiles of RSPOHPMC-based formulations. RPSO and HPMC concentration ranges of 22.1 to $30.3 \%$ and 33.8 to $42.0 \%$, respectively, provided drug sustained release for over $20 \mathrm{~h}$, with $90.56 \pm 0.65$ to 99.09 
Table 2: Physical characteristics (mean \pm standard deviation) of the prepared diltiazem $\mathrm{HCl}$ tablets

\begin{tabular}{cccccc}
\hline $\begin{array}{c}\text { Formulation } \\
\text { code }\end{array}$ & \multicolumn{2}{c}{$\begin{array}{c}\text { Variable level } \\
\text { in coded form }\end{array}$} & $\begin{array}{c}\text { Hardness } \\
\left(\mathbf{k g} / \mathbf{c m}^{2}\right)\end{array}$ & $\begin{array}{c}\text { Drug } \\
\text { content (\%) }\end{array}$ & $\begin{array}{c}\text { Friability } \\
(\%)\end{array}$ \\
\cline { 1 - 4 } & Factor $\boldsymbol{X}_{\mathbf{1}}$ & Factor $\boldsymbol{X}_{\mathbf{2}}$ & & & \\
\hline $\mathrm{DHE}_{1}$ & -1 & -1 & $8.3 \pm 0.4$ & $92.32 \pm 4.20$ & 0.63 \\
$\mathrm{DHE}_{2}$ & -1 & 0 & $8.5 \pm 0.5$ & $90.25 \pm 2.40$ & 0.66 \\
$\mathrm{DHE}_{3}$ & -1 & 1 & $8.6 \pm 0.2$ & $96.43 \pm 5.10$ & 0.53 \\
$\mathrm{DHE}_{4}$ & 0 & -1 & $8.5 \pm 0.1$ & $97.24 \pm 3.30$ & 0.72 \\
$\mathrm{DHE}_{5}$ & 0 & 0 & $8.2 \pm 0.3$ & $94.45 \pm 5.20$ & 0.58 \\
$\mathrm{DHE}_{6}$ & 0 & 1 & $8.3 \pm 0.1$ & $95.14 \pm 3.30$ & 0.69 \\
$\mathrm{DHE}_{7}$ & 1 & -1 & $8.3 \pm 0.2$ & $91.45 \pm 1.50$ & 0.59 \\
$\mathrm{DHE}_{8}$ & 1 & 0 & $8.4 \pm 0.3$ & $93.24 \pm 2.40$ & 0.65 \\
$\mathrm{DHE}_{9}$ & 1 & 1 & $8.5 \pm 0.4$ & $97.32 \pm 4.20$ & 0.61 \\
\hline
\end{tabular}

Table 3: Release of diltiazem $\mathrm{HCl}$ from the test formulations as per factorial design

\begin{tabular}{ccccccccccc}
\hline $\begin{array}{c}\text { Time } \\
\text { (h) }\end{array}$ & \multicolumn{7}{c}{ Formulation code } & \multicolumn{2}{c}{ Diltime SR } \\
\cline { 2 - 8 } & $D H E_{1}$ & $D H E_{2}$ & $D H E_{3}$ & $D H E_{4}$ & $D H E_{5}$ & $D H E_{6}$ & $D H E_{7}$ & $D H E_{8}$ & $D H E_{9}$ & \\
\hline 1 & 22.0 & 20.3 & 18.9 & 19.3 & 18.5 & 17.9 & 18.3 & 17.9 & 15.9 & 17.20 \\
2 & 32.5 & 30.9 & 25.8 & 27.1 & 25.6 & 25.6 & 29.9 & 29.9 & 25.9 & 20.94 \\
3 & 37.8 & 35.9 & 32.6 & 38.6 & 36.0 & 34.0 & 38.0 & 35.9 & 31.9 & 24.48 \\
4 & 41.2 & 39.2 & 36.8 & 41.9 & 40.3 & 34.3 & 42.9 & 43.2 & 39.2 & 28.15 \\
5 & 46.8 & 45.2 & 42.8 & 48.4 & 46.8 & 43.8 & 52.2 & 49.2 & 43.2 & 31.86 \\
6 & 54.1 & 51.6 & 46.3 & 51.0 & 49.3 & 45.3 & 56.0 & 53.3 & 48.3 & 35.39 \\
7 & 60.2 & 58.2 & 53.7 & 55.7 & 53.7 & 50.7 & 60.7 & 57.2 & 52.2 & 38.75 \\
8 & 65.8 & 64.1 & 59.1 & 59.0 & 58.8 & 55.8 & 63.4 & 61.1 & 56.1 & 42.52 \\
9 & 69.4 & 67.0 & 65.4 & 67.7 & 65.9 & 63.9 & 65.5 & 66.0 & 61.0 & 46.89 \\
10 & 73.9 & 71.7 & 68.1 & 71.5 & 69.9 & 65.9 & 71.1 & 70.7 & 65.7 & 50.11 \\
11 & 78.8 & 76.3 & 71.3 & 74.1 & 72.8 & 68.8 & 73.8 & 74.3 & 69.3 & 53.89 \\
12 & 82.6 & 80.6 & 76.3 & 78.3 & 76.8 & 73.8 & 76.3 & 78.0 & 72.0 & 57.24 \\
14 & 86.8 & 85.3 & 82.8 & 83.1 & 81.3 & 78.3 & 82.8 & 82.3 & 78.3 & 63.95 \\
16 & 93.9 & 92.9 & 89.3 & 88.7 & 87.9 & 84.9 & 87.5 & 86.5 & 82.5 & 71.85 \\
18 & 97.6 & 95.4 & 94.8 & 94.4 & 92.8 & 90.8 & 91.1 & 89.2 & 87.2 & 77.98 \\
20 & 99.1 & 98.5 & 97.9 & 97.5 & 96.5 & 95.5 & 94.8 & 93.6 & 90.6 & 85.69 \\
22 & & & & & & & 98.7 & 97.9 & 93.9 & 93.82 \\
24 & & & & & & & & & 98.0 & 99.54 \\
\hline
\end{tabular}

\pm 0.89 drug released, irrespective of the polymer content. Formulation $\mathrm{DHE}_{9}$ containing optimum blend of the polymers, sustained drug release for $24 \mathrm{~h}$ and therefore, was chosen for in vivo studies.

\section{Drug release kinetics}

When the in vitro release data were subjected to kinetic analysis, Higuchi and Korsmeyer-Peppas model gave the highest correlation coefficient $\left(R^{2}\right)$ of 0.996 and 0.995 , and $n$ value of 0.564 , thus indicating that the release mechanism was a combination of diffusion and erosion, i.e., the socalled anomalous drug diffusion. .

\section{In vivo availability}

Drug release from $\mathrm{DHE}_{9}$ was almost similar to that from commercial formulation which was selected. Mean plasma concentration profiles of $\mathrm{DHE}_{9}$ and commercial formulation are presented in Figure 1.

Both the formulations exhibited as sustained release in vivo. All the pharmacokinetics parameters displayed in Table 4. Mean time to reach peak drug concentration ( $T_{\max }$ was $2.05 \pm$ $0.52 \mathrm{~h}$ and $2.30 \pm 0.57 \mathrm{~h}$ for the optimized and commercial formulations, respectively, while mean maximum drug concentration $\left(\mathrm{C}_{\max }\right)$ was $501.74 \pm 0.05 \mathrm{ng} / \mathrm{ml}$ and $509.65 \pm 0.06 \mathrm{ng} / \mathrm{ml}$, 
respectively. The values for $\mathrm{Cmax}, \mathrm{Tmax}, \mathrm{AUC}_{0-\mathrm{t}}$ and AUC $(0-\infty)$ were found to be comparable, indicating that their sustained release patterns were similar.

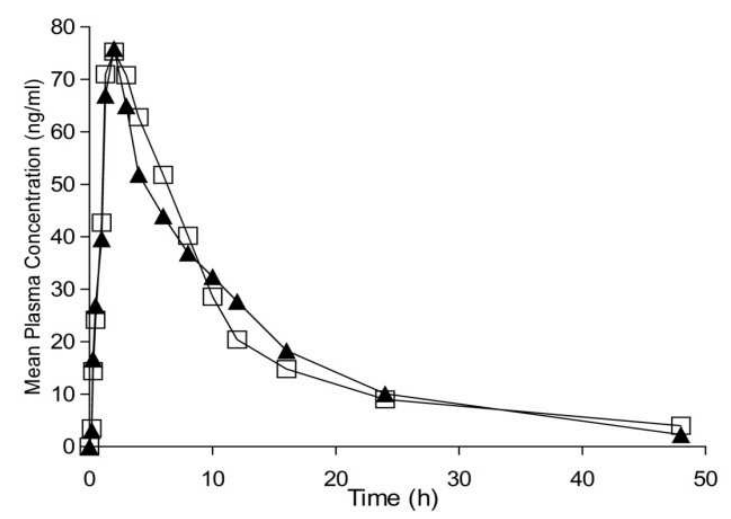

Fig 1: Mean plasma concentration of optimized diltiazem $\mathrm{HCl}$ formulation $(\boldsymbol{\Delta})$ and commercial (reference) product (口)

Table 4: Pharmacokinetic parameters of optimized diltiazem $\mathrm{HCl}$ formulation

\begin{tabular}{|c|c|c|}
\hline Parameter & $\mathrm{DHE}_{9}$ & $\begin{array}{l}\text { Commercial } \\
\text { Formulation }\end{array}$ \\
\hline $\mathrm{C}_{\max }(\mathrm{ng} / \mathrm{ml})$ & $501.74 \pm 0.054$ & $509.65 \pm 0.057$ \\
\hline $\mathrm{T}_{\max }(\mathrm{h})$ & $2.05 \pm 0.52$ & $2.3 \pm 0.57$ \\
\hline $\begin{array}{l}\mathrm{AUC} \\
\left(\mathrm{ng} / \mathrm{ml}^{*} \mathrm{~h}\right)\end{array}$ & $5357.75 \pm 0.214$ & $5424.38 \pm 0.219$ \\
\hline $\begin{array}{l}\text { AUC } \\
\left(\mathrm{ng} / \mathrm{ml}^{*} \mathrm{~h}\right)\end{array}$ & $5622.77 \pm 0.221$ & $5653.22 \pm 0.226$ \\
\hline
\end{tabular}

\section{In vitro/in vivo correlation}

When the in-vitro dissolution of diltiazem $\mathrm{HCl}$ was compared with in-vivo data using the method of linear regression analysis, a correlation coefficient $\left(r^{2}\right)$ of 0.8551 was found, indicating only a fair correlation.

\section{Stability of test formulation}

The stability of the test formulation, stored at 40 ${ }^{\circ} \mathrm{C} / 75 \% \mathrm{RH}$, was monitored over a period of 6 months as per $\mathrm{ICH}$ guidelines and not noticeable changes in its physical appearance, drug content and dissolution profiles were found.. Drug content and dissolution at the end of $24 \mathrm{~h}$ was $97.32 \pm 4.20$ and $98.0 \pm 4.30 \%$, respectively, and thos compares well with $96.22 \pm 3.80$ and 97 $\pm 3.72 \%$ after a period of 6 months.

\section{DISCUSSION}

A suitable sustained release diltiazem $\mathrm{HCl}$ dosage form would not only enhance therapeutic efficacy and patient compliance but also produce more desirable blood drug levels and lower incidence of adverse effects.

The drug content of the formulations ranged from $90.25 \pm 2.40-97.32 \pm 4.20$, indicating good content uniformity for some of the formulations. Furthermore, all the formulations showed satisfactory mechanical characteristics based on hardness and friability data.

The presence of polyvinyl acetate/polyvinylpyrrolidone (Kollidon SR) caused a 'burst' release phenomenon. This can be explained by the high water permeability of Kollidon SR while the presence of Eudragit RSPO and HPMC promoted slow release as drug was released by erosion of the Eudragit matrix and swelling and gelling of the HPMC. Hence, Eudragit RSPO and HPMC K15 M CR were selected for the optimization of drug release.

As the concentration of Eudragit RSPO increased, there was decrease in dissolution rate due to the extremely low water solubility of RSPO whose hydrophobic character caused a delay in the penetration of dissolution medium into the matrix, thereby decreasing drug dissolution and diffusion rate. Since RSPO remains undissolved at various $\mathrm{pH}$ conditions, the polymer also acts as an insoluble barrier to the release of drug from within the matrix.

Generally, the Higuchi order model gave the highest correlation coefficient $\left(R^{2}\right)$ value for the dissolution data. This indicates that the in vitro drug release pattern is not controlled by the amount of drug left in the tablet as dissolution progresses or by the disintegration of the tablet, but by the diffusion. Since Eudragit is also swells, penetration of water does occur due to polymer chain relaxation after prolonged contact with water.

The Korsemeyer-Peppas release exponent (n) value of the optimised formulation ( $\mathrm{DHE}_{9}$ ) is 0.564 , which indicates anomalous drug diffusion [7]. This is means that drug release was both by diffusion and erosion, and this is probably so because HPMC swells to form a gel through which the drug diffuses while the drug is also released by erosion of Eudragit matrix. The optimised formulation $\mathrm{DHE}_{9}$ showed a correlation coefficient of 0.9961 for the Higuchi model indicating a largely diffusion-dependent drug release. In vitro / in vivo correlation was fair with a correlation coefficient $\left(r^{2}\right)$ value of 0.8551 . 


\section{CONCLUSION}

Sustatined release diltiazem $\mathrm{HCl}$ matrix tablet formulation that released drug up to $24 \mathrm{~h}$ has been developed. The tablets showed good bioavailability, stability and physicochemical characteristics. However, further studies are required to scale up the production process to industrial level.

\section{REFERENCES}

1. Merkus FWHM. Controlled and rate-controlled drug delivery. Boca Raton, FL, CRC Press, USA, 1986; 15-47.

2. Langer $R$, Wise D. Medical Application of Controlled Release, Classes of system, Boca Raton, FL, USA: CRC Press, 1984; pp 141-167.

3. Katzung B. Basic and clinical pharmacology. Stamford, CT: Appleton and Lange. 1998: $p 223$.

4. Diez-Pena E, Frutos P, Frutos G, Quijada-Garrido I, Barrales-Rienda JM. The influence of the copolymer composition on the diltiazem hydrochloride release from a series of $\mathrm{pH}$-sensitive poly [( $\mathrm{N}$-isopropylacrylamide)-co-(methacrylic acid)] hydrogels. AAPS Pharm Sci Tech 2004: 20: E33.

5. Korhonen $O$, Kanerva $H$, Vidgren $M$, Urti $A$, Ketolainen J. Evaluation of novel starch acetate-diltiazem controlled release tablets in healthy human volunteers. J Contr Rel 2004; 95: 515-520.

6. Tanaka $Y$, Miyazaki $Y$, Yakou S, Takayama K. Sustained release of highly water-soluble drugs with micelle forming ability from polyionic matrix tablets, Pharmazie, 2007; 62: 41-45.

7. Korsemeyer $R$, Peppas $N$ Macromolecular and modelling aspects of swelling-controlled systems. In, Mansdorf S, Roseman $T$, eds. Controlled Release Delivery Systems, New York, Marcel Dekker, 1983; $p 77$.
8. Tapia C, Escobar Z, Costa E, Sapag-Hagar J, Valenzuela F, Basualto C, Gai MN, YazdaniPedram M. Comparative studies on polyelectrolyte complexes and mixtures of chitosan-alginate and chitosan-carrageenan as prolonged diltiazem clorhydrate release systems, Eur $J$ Pharm Biopharm 2004 ; 57: 65-75.

9. Varshosaz J, Tavakoli N, Ali Eram S. Use of natural gums and cellulose derivatives in production of sustained release metoprolol tablets, Drug Del 2006; 13: 113-119.

10. Vargas $C$, Ghaly $E$, Kinetic release of theophylline from hydrophilic swellable matrices, Drug Dev Ind Pharm 1999; 25: 1045-1050.

11. Katzhendler I, Mader K, Friedman M. Structure and hydration properties of hydroxypropyl methylcellulose matrices containing naproxen and naproxen sodium, Int J Pharm 2000; 200: 161-179.

12. Makhija S, Vavia $P$. Once daily sustained release tablets of venlafaxine, a novel antidepressant, Eur $J$ Pharm Biopharm 2002; 54: 9-15.

13. Ceballos A, Cirri M, Maestrelli F, Corti G, Mura P. Influence of formulation and process variables on in vitro release of theophylline from directlycompressed Eudragit matrix tablets, II Farmaco 2005; 60: 913-918.

14. Patra $C$, Kumar A, Pandit H, Singh S, Devi M. Design and evaluation of sustained release bilayer tablets of propranolol hydrochloride, Acta Pharm 2007; 57: 479-489.

15. The United State Pharmacopoeia, The National Formulary, (USP 30-NF 25) The official compendium of standards, Asian edition, United State Pharmacopoeial Convention Inc., Rockville, MD. 2007; 1913-1914..

16. Guidelines for bioavailability and bioequivalence studies. Central Drugs Standard Control Organization, DGHS, Ministry of Health and Family Welfare, Government of India, New Delhi. 2005.

17. Yuskel N, Kanik A, Baykara T. Comparison of in vitro dissolution profiles by ANOVA-based, modeldependent and independent methods, Int $J$ Pharm 2000; 209: 56-67. 